\title{
AS PÁGINAS DE HISTÓRIA
}

\author{
M aria Arlete Zülzke Hö öling*
}

Competência em educação é mobilizar um conjunto de saberes para solucionar com eficácia uma série de situações.

(Perrenoud)

\begin{abstract}
RESU M 0: Produzimos um material para o estudo da localidade num Atlas M unicipal Escolar, objetivando despertar a curiosidade e o gosto pelo conhecimento da história local. D estacamos nas páginas de história do Atlas de Rio Claro o processo de ocupação, povoamento, doação de sesmarias, desmembramento em fazendas, a canade-açúcar, o café, o escravo, o imigrante e as mudanças que ocorreram em Rio Claro até 0 início do século XX.

Palavras-chave: Ensino de história. Atlas escolares. U so de mapas. $\mathrm{H}$ istória local.
\end{abstract}

\section{HISTORY PAGES}

ABST RACT: Produced for a municipal school atlas, this material on our local ity seeks to awaken the curiosity and liking for knowledge on local history. These history pages of the Atlas of Rio Claro highlight the occupation and populating processes, the attribution of sesmarias (lands given by the Kings of Portugal), their division in fazendas, as well as the sugar cane, coffee, slaves, immigrants and the changes that took place in Rio Claro until the beginning of the $X X^{\text {th }}$ century.

Key words: $\mathrm{H}$ istory teaching. School atlases. U se of maps. Local history.

* G raduada em H istória e professora da rede estadual de ensino. E-mail: mazhofling@hotmail.com 
E ste projeto de pesquisa foi um desafio que um grupo de professores da rede pública de ensino realizou em parceria com a universidade. 0 retorno à universidade foi também uma oportunidade para a reconstrução de nossa identidade profissional, para a valorização e o reconhecimento dos professores da escola pública. Refletimos nossas práticas escolares, enfrentamos novos desafios e questionamos muito os saberes de nossos alunos. A angústia foi grande, realizamos uma abordagem crítico-reflexiva, produzimos material para o estudo da localidade num Atlas M unicipal Escolar para ser usado por alunos do ensino fundamental (3a a 6a série).

N ossa proposta foi produzir um material sobre a história do município. Foi um esforço corajoso, pois tivemos uma certa dose de ousadia para a realização dessa prática inovadora. Apresentamos um material escolar que permite ao aluno e ao professor refletir sobre 0 processo histórico de como se formou o município de Rio Claro. Permite reconstruir não só o passado, mas também sugere pistas, estabe lece relações, direções para novas pesquisas, sensibiliza alunos para leituras das paisagens do cotidiano.

O s temas el encados para o Atlas M unicipal Escolar foram resultado do estudo das propostas curriculares publicadas pela SEE-SP, de uma pesquisa realizada com professores da D elegacia de Ensino de Rio Claro para levantamento do interesse sobre atlas escolares e da leitura dos PCNS.

0 recorte temático concentrou-se no processo de ocupação e povoamento da região, por sugestão de nossa coordenadora, que é especialista em geografia. 0 ensino de história a partir de eixos temáticos possibilita a compreensão do passado, permite questionamentos e análise dos problemas atuais do cotidiano, possibilitando debates.

O s temas da história deveriam responder à questão da ocupação do território local: “D e que maneira o processo de ocupação do território paulista, no contexto da colonização do Brasil, explica a ocupação da região onde hoje está o município de Rio Claro? 0 que existia nessa região antes de surgir a vila? Como se deu a ocupação deste território, que interesses moviam os primeiros colonos que aqui se fixaram?"

0 Atlas M unicipal Escolar foi construído por eixos temáticos porque favorece relações de semelhanças, diferenças, permanências e transformações em épocas distintas. A partir do cotidiano do aluno 0 professor prioriza temas para que ele se identifique em outras dimen- 
sões históricas. É possível selecionar os conteúdos de história e articulá-los de tal forma que permita ao aluno questionar, refletir sobre sua realidade.

0 ensino de história deve estar vinculado à vivência do aluno (Proposta Curricular para o Ensino de H istória, SEE-SP; 1992); a informação pronta e acabada faz do aluno um ser passivo com relação ao saber e distante do processo histórico. Para que ele seja atraente e participante na sociedade é fundamental que entenda os processos de produção do conhecimento. 0 ensino de história mudou muito nos últimos anos, e os alunos são considerados participantes ativos na construção do conhecimento. D eve-se estabelecer relações, construir noções de diferenças e semelhanças, de continuidade e permanência. Comparar acontecimentos no tempo, tendo como referência os conceitos de simultaneidade e tempo/espaço.

Buscando a história local, a leitura do Atlas Municipal Escolar pretende despertar nos alunos a topofilia, o interesse pela história de sua cidade ou da cidade em que moram, a busca de sua identidade e de sua cidadania. Permitirá também reviver o clima de uma época, a saudade de um tempo.

Até então, nas escolas de Rio Claro, a história da cidade era "contada" próximo do aniversário da cidade, 24 de junho, com textos superficiais. As páginas do Atlas de Rio Claro permitem identificar os primeiros habitantes da cidade, a cultura, as formas de trabalho em diferentes épocas, os meios de transporte, agricultura, indústria, a relação entre cidade e campo. 0 professor deve localizar e destacar os processos de trabalho no presente e no passado, do escravo ao operário.

Ensinar história é estimular os alunos a refletirem e fazerem descobertas valorizando o saber do aluno. A história não existe apenas nos livros, ela é real; por meio de relatos de pais, avós, o aluno pesquisa, seleciona e produz um texto informativo. Essa nova maneira de ensinar história muda o foco: dos grandes homens e seus feitos para as pessoas comuns e seu cotidiano. Entram em cena os costumes da vida real que diminuem também a distância com relação ao passado: os alunos deixam de ver a história fragmentada e passam a vê-la como um todo do qual fazem parte.

A pesquisa é um meio para se retomar todo o processo histórico, e a escola deve ser sinônimo de atuação, de crescimento, reconhecimento e de alunos felizes descobrindo o valor de sua própria história como indivíduos atuantes no mundo em que vivem. "Produzir 
H istória é procurar captar, recuperar relações que se estabelecem entre os grupos humanos no desenvolvimento de suas atividades, nos mais diferentes tempo e espaço" (C abrini, 1986).

A reconstrução da história de um local é trabalho amplo, desencadeia um conjunto de forças no imaginário individual e coletivo de todos. A história não existe apenas nos livros, ela é real e viva. A escola pode convidar os avós para conversar com os colegas de seus netos sobre sua infância. Esses encontros possibilitarão um passado construído no relatar do dia-a-dia desses velhos, como viviam na cidade, as brincadeiras de rua numa época em que a rua ainda era local de crianças brincarem.

A preservação da memória, a reconstrução do passado, leva as pessoas a terem um novo olhar diante do velho, do antigo, das marcas do passado, o novo e 0 velho juntos. O lhar a cidade com outro olhar...

Encontramos também material de pesquisa, dados e informações em fontes no Arquivo Público e H istórico de Rio Claro "O scar de Arruda Penteado", "Iugar da memória", nos dizeres de Pierre N ora, onde estão disponíveis documentos originais catalogados que remontam a 1845: atas das C âmaras M unicipais, certidões, processos do Poder Judiciário, passaportes e outros. Há também um rico acervo fotográfico mostrando o lugar, o cotidiano das pessoas, obras de canalização, festas cívicas etc.

Estudar a história de Rio Claro é pesquisar documentos, sítios arqueológicos, almanaques, mapas, fotografias, filmes de época, pinturas, vestuário, objetos, jornais, revistas, móveis... encontrados também no M useu Histórico e Pedagógico "Amador Bueno da Veiga", situado em Rio Claro.

M uitas leituras, pesquisas e discussões aconteceram nas reuniões semanais na elaboração do atlas. Fomos buscar a história de Rio Claro na história da Capitania de São Vicente, depois Capitania de São Paulo.

Pobre em recursos produtivos, isolada do circuito comercial em função da barreira natural da Serra do M ar, a economia de São Paulo no período colonial teria sido limitada a uma modesta policultura de subsistência. Essa penúria generalizada teria sido causa suficiente para estimular os paulistas a passar anos a fio em remotos sertões em busca do "remédio para a sua pobreza", no dizer da época. $\mathrm{N}$ a fal ta de jazidas de ouro e de prata, este remédio teria sido o índio cativo. Arrancado das missões jesuíticas e vendido para os senhores de engenho do litoral nordestino. (C unha, 1998.) 
$\mathrm{N}$ a historiografia referente à Capitania e Província de São PauIo, lemos os clássicos de Sérgio Buarque de H olanda, Emília Viotti da C osta, C aio Prado Júnior... Fomos buscar a história de Rio Claro em autores como Warren $\mathrm{D}$ ean, Thomas $\mathrm{D}$ avatz, $\mathrm{O}$ dilon N ogueira de $M$ atos...

São leituras significativas para entendermos como o território foi ocupado, como se formou a população, reconstituindo os caminhos percorridos pela ocupação e a conquista do território nacional, ultrapassando o litoral e os limites estabelecidos pelo Tratado de Tordesilhas (1494).

Encontramos nessas leituras referências à história da Capitania e da Província de São Paulo seu processo de formação territorial no Brasil Colonial, bem como os caminhos percorridos pelos paulistas na busca da mão-de-obra indígena e da mineração, encontrando as justificativas para a mobilidade dessa população que vivia distante dos centros de consumo.

0 ensino da história permite valorizar o saber do aluno. Ele terá mais facilidade em compreender o processo histórico se o professor partir de problemas locais em que ele está inserido (escola, família, vizinhos, amigos) fazendo a relação destes com situações de uma amplitude maior.

As páginas do Atlas de Rio Claro despertam o interesse pela história local, destacando a importância das fazendas de café. U ma visita programada é uma prática pedagógica que sugere saídas da sala de aula para visitas a museus, arquivos ou fazendas, conhecendo pontos da cidade e da região. Esses momentos são oportunidades de um encontro com o passado e permitem que todos se coloquem diante de situações diferentes, estimulando interesse e participação. Proporcionam contatos diretos com fontes e documentos históricos, permitindo também discussões sobre a relação passado e presente, preservação do patrimônio. 0 professor, valorizando o saber do aluno, sua bagagem cultural, permite que ele relacione assuntos atuais com 0 passado, utilizando-se de documentos pessoais e familiares para produzir a sua história, reconhecendo neles documentos da história do lugar em que vive.

As páginas de história do Atlas M unicipal Escolar iniciaram-se com informações sobre Sinais dos Primeiros H omens, Sítios Arqueológicos e $\mathrm{O}$ s Primeiros $\mathrm{H}$ abitantes. ${ }^{1} \mathrm{O}$ assunto é difícil para as classes iniciais, mas não poderíamos deixar de mencionar que no M unicípio 
de Rio Claro se encontram inúmeros sítios que, na década de 1960, foram estudadas por arqueólogos como M aria C. Beltrão, Tom M iller e Fernando Altenfelder.

A O cupação do território paulista ocorrida nos séculos XVI, XVII e XVIII foi abordada em conjunto para os três municípios envolvidos na pesquisa - I peúna, Rio Claro e Limeira -, porque o projeto de ocupação foi muito semelhante em toda a região onde eles se situam. O território hoje ocupado por esses três municípios se constituía em "áreas de passagem" no processo de ocupação da Capitania e da Província de São Paulo.

A descoberta do ouro em M ato Grosso, em 1718, fez dessa região uma área de passagem no caminho terrestre para as minas: abrigo, pouso para bandeirantes, viajantes, tropeiros. Esses pousos e ranchos foram embriões de muitos povoados, depois vilas como Rio Claro e Limeira. Rio Claro passou a ser conhecido como "boca de sertão", porque depois deles era, para quem vinha do litoral, o sertão de Araraquara, ainda não ocupado.

$\mathrm{N}$ esse momento a pesquisa recaiu sobre as fontes históricas de Piracicaba ou Vila N ova Constituição, a vila de onde Rio Claro se desmembrou. Mostramos a reconstituição do caminho de Luis Pedroso de Barros, feita após a leitura da carta (com base em Perecin, 1991) em que ele descreve o caminho, citando rios e relevo. Essa representação constituída de maneira inovadora, baseada em um texto escrito, foi "lida" pelo grupo de pesquisa e transformada em outra linguagem: um mapa, presente na página 23 do Atlas de Rio Claro com a denominação de "Reconstituição do caminho de Luis Pedroso".

0 povoamento da região onde hoje está R io Claro ocorreu em vários momentos, que vieram a ser, cada um deles, o título/tema de uma página do atlas. A divisão em quatro momentos distintos foi tributária da leitura dos clássicos da historiografia paulista e brasileira já citados acima.

O Início do povoamento, que trata do avanço da lavoura da canadeaçúcar para o interior, dos tropeiros parando por aqui rumo às minas, da construção de um pouso e de uma capela que foi o núcleo inicial do povoamento de Rio Claro. A 10 de junho de 1827, o povoado foi elevado a Capela Curada de São João Batista do Ribeirão Claro, abrigando uma população de homens livres e escravos.

$D$ as sesmarias às fazendas, tratando de como, para acelerar a ocupação das terras, o governador da Província de São Paulo concedeu 
sesmarias, que eram os únicos títulos de terra reconhecidos no período colonial e início do Império. Essas sesmarias, do Corumbataí e do M orro Azul, desmembraram-se originando muitas fazendas, nas quais se plantava basicamente cana-de-açúcar com mão-de-obra escrava e transporte em tropas de mulas. D e 1850 a 1900, a lavoura da canade-açúcar foi substituída pelo café, o escravo foi substituído pelo imigrante, as mulas pelas ferrovias, e o número de fazendas aumentou de 56 para 152.

A Formação da Vila caracteriza Rio Claro no século XVIII como um pouso localizado nas terras do sertão do M orro Azul, local de passagem. A crise na mineração fez o governo paulista reativar a lavoura de cana-de-açúcar e doar sesmarias para incentivar o povoamento da região. A crise na exportação do açúcar levou os fazendeiros do interior paulista a substituir a cana pelo café. Era essencial manter um produto de exportação.

O café chega a Rio Claro nas páginas: Rio Claro e o Café; As fazendas de café; I migração; Rio Claro de outrora; Rio-clarenses de outrora. N essas páginas, as fotografias pesquisadas no Arquivo Público contam a história de Rio Claro. Após 1840 o café foi plantado em quantidade significativa no antigo 0 este Paulista - de Campinas até Rio Claro. Em meados do século XIX o número de fazendas aumentou. As de Rio Claro destacaram-se na produção. O s fazendeiros detinham o poder local, eram intermediários da população com o governo, ocupando cargos importantes na política imperial, apesar de muitos terem se tornado defensores de um regime republicano.

A produção das fazendas era comercializada pelas casas comissárias; o transporte até o porto de Santos tinha um alto custo e era precário. As fazendas de café eram quase auto-suficientes: trouxeram luxo e prestígio para o interior. A ferrovia, organizada com capital cafeeiro, chegou a Rio Claro em 1876, deixando a cidade de ser "boca de sertão" passando a ser conhecida como "ponta de trilho" até 1884, quando os trilhos ultrapassaram os limites da cidade. A localização das estações de trem dependia da influência política dos fazendeiros.

A extinção oficial do tráfico negreiro fez os fazendeiros investirem o capital na ferrovia que mudou a paisagem da cidade, que se transformou num centro de produção e comércio das regiões interioranas. Em 1892 foram criadas, em Rio Claro, as oficinas da Companhia Paulista de Estradas de Ferro. Durante muitos anos a cidade dependeu e viveu em função dessas oficinas e da ferrovia. 
0 trabalho escravo foi o sustentáculo da produção cafeeira até 1880, depois foi substituído pelo do imigrante. Rio Claro foi um dos primeiros municípios paulistas a utilizar o imigrante como mão-deobra. A partir de 1885, imigrantes alemães e italianos vieram sob a responsabilidade do governo. Ficavam na H ospedaria dos Imigrantes, na cidade de São Paulo, até serem contratados pelos fazendeiros. Com 0 desmembramento das fazendas da região, muitos imigrantes passaram a morar na cidade de Rio Claro, originando bairros típicos, dedicando-se a pequenas indústrias e ao comércio.

O s escravos, os imigrantes, os fazendeiros trouxeram hábitos e costumes, que deixaram marcas profundas na história e no cotidiano de Rio Claro. M esmo o atlas não tendo uma página sobre o trabalho escravo na região, é impossível falar sobre cana-de-açúcar e café sem mencionar e refletir sobre escravidão, momento significativo na história. Talvez na próxima edição...

\section{Considerações finais}

A reconstrução da história de Rio Claro foi possível porque buscamos sua origem na ocupação do território brasileiro lendo autores clássicos da nossa historiografia. Respondemos à pergunta proposta por nossa coordenadora do projeto, "como ocorreu a ocupação dessa região", percorrendo o caminho da história da Capitania e da Província de São Paulo e atingimos o estudo da região e da localidade de Rio Claro.

A nossa grande dificuldade foi questionar as informações, problematizar. 0 que era novo? 0 que se conhecia? 0 que queríamos que os alunos aprendessem com o Atlas M unicipal Escolar? Como selecionar as informações? Às vezes não chegávamos a resposta al guma... N osso objetivo era fazer um Atlas M unicipal Escolar interdisciplinar como possibilidade de ensino da localidade. É sempre bom falar da história local mesmo que ela não tenha papel relevante nos eventos nacionais, porque toda mudança histórica traz reflexos no cotidiano das pessoas.

Estudar por meio de eixos temáticos favorece estudos de processos e relações de semelhanças, diferenças, permanências e transformações em épocas distintas. $\mathrm{N}$ ão é possível ensinar tudo; o professor deve priorizar os temas que serão estudados durante 0 ano. No ensino fundamental, estudar história pelos eixos temáticos do cotidiano permite ao aluno ampliar sua capacidade de observação do mundo 
que 0 rodeia e diversificar suas relações. $0 \mathrm{~s}$ assuntos trabalhados em sala de aula permitem estabelecer relações com o dia-a-dia dos alunos. 0 professor deve e pode dar vida aos fatos do passado para que 0 aluno possa relacioná-los com os fatos atuais. Abordando a história pelo tempo presente 0 aluno terá mais facilidade para entendê-la, sendo esta mais significativa, envolvendo-o em seus temas.

Atualmente se estuda uma nova historiografia que revela um Brasil dinâmico, uma história de vencidos e vencedores, de pobres e de ricos, que permite um estudo mais interessante e diversificado.

A realização desse projeto de pesquisa foi possível porque Rio Claro teve seus arquivos preservados, muitos até catalogados. Há "coleções" de políticos locais ligados ao Partido Republicano Paulista (PRP), atuantes no período da República Velha. E inúmeros periódicos (jornais, almanaques, revistas, boletins, anais...) antigos, até um velho jornal de 1873, informando sobre o cotidiano da cidade, há quase dois séculos.

U ma das contribuições mais enriquecedoras da pesquisa foi o uso de imagens fotográficas como registro. A fotografia deixou de ser ilustração de texto para se tornar um documento. É um ponto de partida para desvendarmos o passado. 0 Atlas M unicipal Escolar permite visitar um lugar por intermédio da leitura de fotografias, gera um espaço diferente de aprendizagem, uma prática diferente para estudar a localidade, que pode ser enriquecida ainda mais com "estudos do meio" que se utilizem das fotografias como maneira de registrar o local visitado.

0 estudo do meio coloca a realidade dentro da sala de aula e tira os alunos da escola. N ão é preciso viajar: numa volta ao bairro, ao Arquivo da cidade, ou até mesmo em volta da escola, aprende-se muito. É importante para esse estudo o trabalho em equipe dos professores e os saberes dos alunos, por exemplo, sobre as marcas do passado ainda presentes nas paisagens de seu cotidiano.

0 estudo do meio por intermédio do trabalho de campo como prática pedagógica torna mais próximo o conhecimento que os alunos estão adquirindo. 0 estudo com o Atlas M unicipal aproximou a realidade. 0 s trabal hos de campo devem privilegiar locais significativos que permitirão ao professor retomar assuntos estudados. É importante levar os alunos a se apropriarem do lugar, observando as alterações provocadas pela passagem do tempo.

Recebido em abril de 2003 e aprovado em maio de 2003. 


\section{N ota}

1. As frases em destaque que aparecerão no texto daqui para frente são coincidentes com os títulos das páginas do Atlas M unicipal Escolar de Rio Claro.

\section{Referências bibliográficas}

BRASIL. M inistério de Educação e D esporto. Secretaria de Educação Fundamental. Parâmetros curriculares naci onais: história. Brasília: MEC/SEF, 1998.

CABRIN I, C. 0 ensino de história. São Paulo: Brasiliense, 1986.

COSTA, E.V. Da senzala à colônia. São Paulo: Difel, 1966.

CU N H A, M.C. (O rg.). História dos índios no Brasil. São Paulo: Cia das Letras, 1998.

DAVAT Z, T. M emórias de um colono no Brasil: 1850. Belo H orizonte: Itatiaia, 1980.

DEAN, W. Rio Claro: um sistema brasileiro de grande lavoura, 18201920. Rio de Janeiro: Paz \& Terra, 1977.

H OLAN D A, S.B. História geral da civilização brasileira. São Paulo: Difel, 1960. v.1-2.

M ATOS, O.N . Café e ferrovias: a evolução da ferrovia de São Paulo e o desenvolvimento da lavoura cafeeira. Campinas: Pontes, 1990.

N O RA, P. Entre memória e história. Projeto H istória, São Paulo, n. 10, dez. 1993. N úmero temático: H istória e Cultura.

PERECIN , T.G. Picadão de M ato G rosso: contribuição à história de Piracicaba. G ênese Paulista (1 de uma série de 4). Jornal de Piracicaba, Piracicaba, 01 ago. 1991.

PRAD O JÚ NIOR, C. Formação do Brasil contemporâneo. São Paulo: Brasiliense, 1963.

PRADO JÚNIOR, C. História econômica do Brasil. São Paulo: Brasiliense, 1973.

SÃO PAULO (Estado). Secretaria de Educação. Coordenadoria de Estudos e N ormas Pedagógicas. Proposta curricular para o ensino de história: 1o grau. São Paulo: SEE/Cen P, 1988. 